\title{
ADAPTIVE GEOGRAPHICAL VARIATION IN BILL SHAPE OF SCRUB JAYS (APHELOCOMA COERULESCENS)
}

\author{
A. Townsend Peterson \\ Center for Evolutionary and Environmental Biology, Field Museum of Natural History, Roosevelt \\ Road at Lake Shore Drive, Chicago, Illinois 60605-2496
}

Submitted July 8, 1991; Revised July 17, 1992; Accepted July 22, 1992

\begin{abstract}
The hypothesis of an adaptive basis to geographical variation in scrub jay bill shapes was tested using morphometric and phylogenetic approaches. Bill shapes of scrub jays include a short, hooked form and a long, pointed form, at least in females. The variation is closely associated with habitat use across the species' range: populations living in oak woodlands have short, hooked bills, whereas populations living in pinyon-juniper woodlands have long, pointed bills. The short, hooked form is apparently the primitive (pleisiomorphic) state in the species. The pointed form probably has been derived twice and lost once during the phylogenetic history of the species, each derivation being associated with invasion of pinyon-juniper woodlands and the loss with invasion of oak woodlands. Each bill form is most efficient at exploiting the foods present in the habitat with which it is associated, according to behavioral observations and functional arguments. Hence, the hypothesis that the variation is adaptive is strongly supported. A historical geographical scenario for the adaptive evolution of bill shape in scrub jays is presented.
\end{abstract}

The study of geographical variation has been central to the development of the present understanding of evolutionary processes (Mayr 1963; Gould and Johnston 1972). Until recently, geographical differences were generally assumed to reflect adaptation to selection pressures in different environments (see, e.g., James 1970). However, Gould and Lewontin (1979) pointed out that alternatives to adaptive explanations (e.g., phenotypic plasticity, habitat sorting) should also be considered. Hence, geographical variation should be tested against a null model of no adaptive basis before adaptive explanations are invoked. A careful consideration of empirical, theoretical, and philosophical implications of such tests is presented by Brandon (1990).

Empirically, several approaches can be used to test aspects of adaptive hypotheses regarding morphological variation among individuals or populations (Endler 1986). The most circumstantial test involves (1) a search for associations between habitat and form (Felsenstein 1985; Mayr 1988). The hypothesis that such associations result from adaptation can be strengthened by (2) demonstration of independent evolutionary derivations of a form in similar ecological situations (Brooks and McLennan 1991; Harvey and Pagel 1991), (3) demonstration of similar structural patterns in other species with similar ecological habits (Zink and Remsen 1986), and (4) identification of causal factors in the environment (Zusi 1987). 
Finally, (5) experimental (Benkman 1988) and (6) functional morphological (Bock 1966) approaches are useful in demonstrating actual functional advantages and identifying causal agents.

The purpose of this study is to test the hypothesis that geographical variation in bill shape of scrub jays (Aphelocoma coerulescens) represents an adaptation to exploiting the habitats in which they live. My approach in this article consists of a combination of four of the six tests of adaptive hypotheses listed above (all except 3 and 5). I begin with a search for form-habitat associations (test 1) and then incorporate phylogenetic information on the species from biochemical studies (Peterson 1992) to test for multiple derivations in similar ecological situations (2). Finally, I attempt to identify causal factors in the different habitats through observations of behavior (4) and functional considerations (6).

\section{BILL SHAPE IN CORVIDS}

The avian family Corvidae is a diverse assemblage of about 100 species. The majority of the species, as well as putative sister groups (e.g., Paradisaeidae) (Hope 1989), have a heavy bill with a hooked tip and are omnivores, eating a wide variety of insects, small vertebrates, seeds, and fruit (Goodwin 1976). A few species have specialized ecologically on foods such as acorns or pine seeds or on modes of feeding involving digging in the ground (Turcek and Kelso 1968; Goodwin 1976). The digging species (Podoces spp., Pyrrhocorax pyrrhocorax, and Corvus capensis) have long, curved bills; the pine seed specialists have straight, pointed bills (e.g., Gymnorhinus cyanocephalus, Nucifraga spp.); and the acorn specialists have retained the hooked bill form (e.g., Cyanocitta cristata, Garrulus glandarius). These broad associations suggest that bill shape in corvids is related to exploitation of particular food types.

Previous studies have suggested that bill structure is an important adaptive feature of corvid morphology. Bock (1966) argued that features of the structure and shape of skulls of crows (Corvus brachyrhynchos) serve to distribute biting stresses to the ventral part of the cranium, which avoids stress to delicate parts of the brain case. Zusi (1987) demonstrated that a buttress at the base of the mandible of most species of New World jays braces the partly opened lower jaw, which enhances its utility as a pounding tool. Hence, further investigation of the adaptive nature of variation in bill structure in corvids is of interest.

Scrub jays range in western North America from Oregon and Wyoming south to southern Mexico and from Texas and Colorado west to the Pacific coast, with disjunct populations in peninsular Florida and on Santa Cruz Island off the coast of southern California (fig. 1) (Pitelka 1951). Scrub jays exhibit geographical variation in a number of characters, including size and shape of the bill, which varies from relatively short and hooked to long and pointed (Pitelka 1951). Scrub jays generally live in either oak or pinyon-juniper woodland or in a mosaic or mixture of the two habitats (fig. 1) (Pitelka 1951). In some peripheral areas, they live in other habitats, such as desert scrub, riparian woodlands, alpine forest, and mangroves (Peterson and Vargas 1993). A considerable portion of scrub jay life history is centered around harvesting and storing large, fleshy nuts, such as 


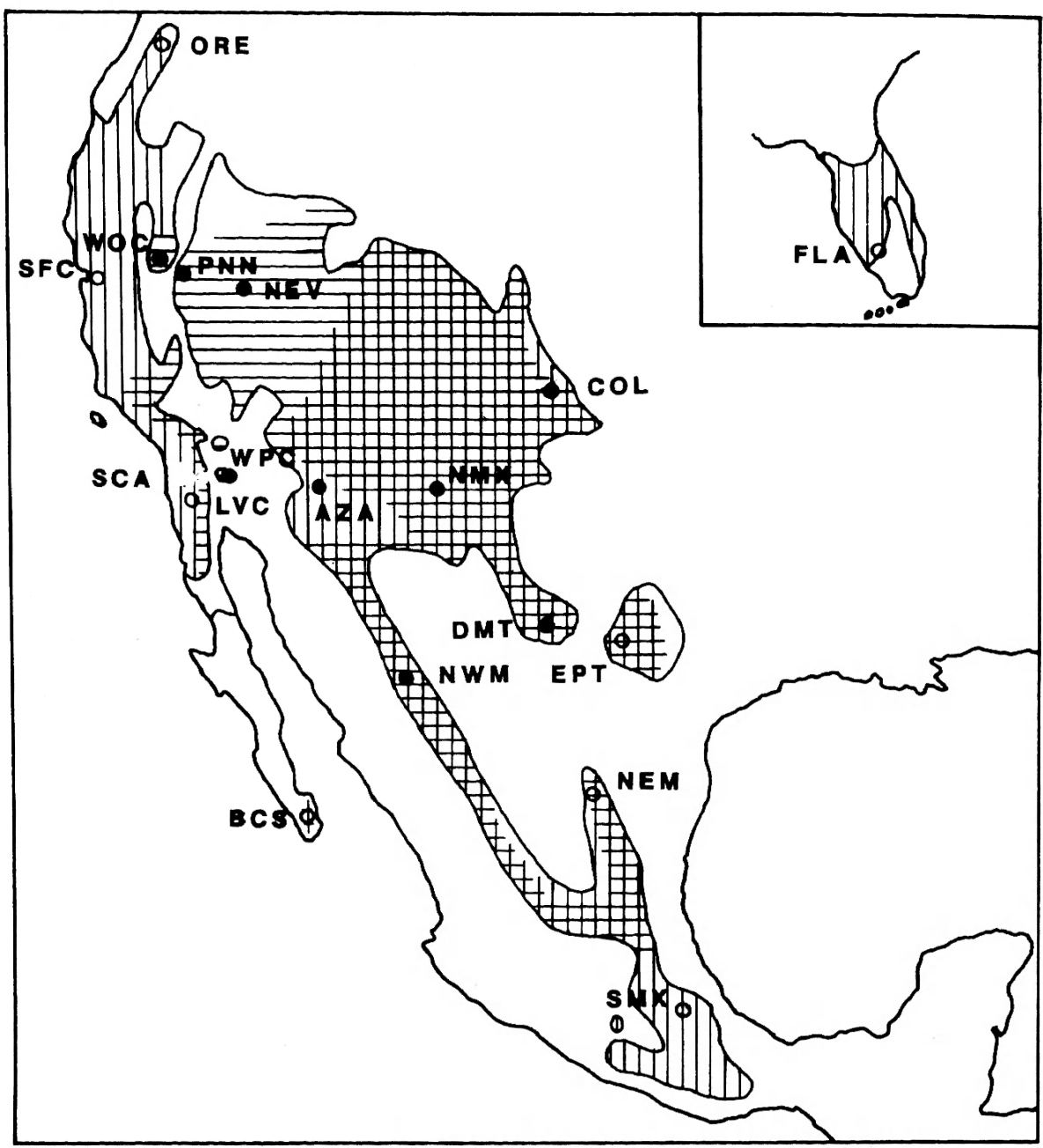

Fig. 1.-Distribution of scrub jays and sample points for this study, showing approximate extent of pinyon (horizontal lines) and oak (vertical lines) habitats. Unmarked areas within the species' range are areas in which the jays live in other habitats. Symbols for sample points indicate jay habitat use as oak woodland (open circles) vs. pinyon woodland (closed circles).

acorns or pinyon nuts (Vander Wall and Balda 1981; Woolfenden and Fitzpatrick 1984; DeGange et al. 1989; Vander Wall 1990). Given that scrub jays are highly genetically structured across their geographical range (Peterson 1990a), adaptations for exploiting different habitats efficiently are to be expected (Peterson and Vargas 1993).

METHODS

\section{Geographical Variation}

I measured aspects of bill shape of 140 study skins in the collections of the Field Museum of Natural History taken from 18 localities throughout the species' 
range (fig. 1). Habitat designations for localities generally follow Peterson and Vargas (1993), but where mosaics of habitats are present I chose a priori the habitat in which jay densities were highest during actual field visits (table 1) (A. T. Peterson, unpublished manuscript). Sample sizes were small owing to the time-intensive nature of some of the measurements. Sex, age (fledgling, secondyear, after second-year) (Pitelka 1945), and season (March-May, June-August, September-November, December-February; seasonal breakdown chosen to coincide with schedules of breeding and molt from Pitelka 1945) were recorded from each specimen. I used seven measurements to characterize bill shape: LENGTH, maxilla length measured from the anterior edge of the nostril; DEPTH, bill depth measured at the anterior edge of the nostril; WIDTH, maxilla width measured at the anterior edge of the nostril; HOOK, length of the bill hook; and the three parameters of a second-degree polynomial approximation to the tangent-angle function (Bookstein 1978) of the culmen (PARAMA, PARAMB, PARAMC). Details of measurement of the latter four characters are given below.

I pinned each specimen so that its bill was positioned horizontally at a standard height under a dissecting microscope and then sketched a lateral view at $6 \times$ magnification using a drawing tube (fig. 2). I measured HOOK as the distance to which the tip of the bill was depressed below the rostral extension of the straight maxillary tomium on these standard-sized drawings.

To describe variation in the curvature of the culmen, I digitized the drawings and extracted tangent-angle functions (Bookstein 1978) from the curvature of the culmen. I positioned the drawings on a digitizing pad with the maxillary tomium along the horizontal, and I marked points every $1 \mathrm{~mm}$ in the horizontal direction. The tangent-angle function consists of the relationship between the angle of the line tangent to a curve and the arc distance along the curve to a point of reference (Bookstein 1978). Using the digitized coordinate data, I estimated the tangentangle at the $n$th point using a symmetrical-difference equation (B. F. Plybon, personal communication):

$$
\theta_{n}=\operatorname{ATN}\left[\frac{y_{n+1}-y_{n-1}}{x_{n+1}-x_{n-1}}\right]
$$

in which ATN indicates the arctangent of the quantity in brackets. For all points except the first and the last (for which $\theta_{n}$ is undefined), this formula gives an unbiased estimate of $\theta_{n}$ if the points are evenly spaced along the $X$-axis. I calculated the arc distance from the $n$th point to the bill tip as

$$
D_{n}=\sum_{i=1}^{n} \sqrt{\left(y_{i}-y_{i-1}\right)^{2}+\left(x_{i}-x_{i-1}\right)^{2}} .
$$

Finally, I fitted polynomial regressions to each tangent-angle function using an orthogonal least-squares polynomial algorithm from Hood (1987). I found seconddegree polynomial approximations of the form $y=A x^{2}+B x+C$ to be the best balance between fitting the data accurately and estimating too many parameters (fig. 3). I then used the parameters $\mathrm{A}, \mathrm{B}$, and $\mathrm{C}$ of each regression equation as characters describing the curvature of the culmen of each bill. 
TABLE 1

Summary of Sample Abbreviations, Localities, Habitats, Numbers of After Second-Year Individuals, and Population Means ( \pm SE) for Five Characters Describing Bill Shape

\begin{tabular}{|c|c|c|c|c|c|c|c|c|}
\hline Abbreviation & Locality & Sex & $\begin{array}{c}\text { Sample } \\
\text { Size }\end{array}$ & LENGTH & DEPTH & WIDTH & HOOK & PARAMC \\
\hline \multicolumn{9}{|c|}{ Oak woodlands: } \\
\hline \multirow{2}{*}{ ORE } & Oregon & $\mathbf{M}$ & 1 & 19.60 & 9.17 & 9.65 & 8.0 & 1.127 \\
\hline & & $\mathrm{F}$ & 2 & $19.15 \pm .84$ & $8.46 \pm .05$ & $9.11 \pm .07$ & $8.5 \pm 1.5$ & $1.055 \pm .042$ \\
\hline \multirow[t]{2}{*}{ SFC } & California, San Francisco & $\mathbf{M}$ & 2 & 18.60 & 8.77 & $8.68 \pm .13$ & $14.0 \pm 2.0$ & $1.180 \pm .138$ \\
\hline & & $\mathrm{F}$ & 3 & $19.08 \pm .37$ & $8.95 \pm .03$ & $9.26 \pm .22$ & $11.3 \pm 1.9$ & $1.122 \pm .03$ \\
\hline SCA & California, southern & $\mathbf{M}$ & 2 & $19.54 \pm 1.1$ & & $8.82 \pm .33$ & $9.0 \pm 1.0$ & $1.056 \pm .021$ \\
\hline \multirow[t]{2}{*}{ LVC } & California, Love Valley & $\mathbf{M}$ & 2 & $18.69 \pm .42$ & $8.74 \pm .10$ & $8.18 \pm .09$ & $10.5 \pm .5$ & $1.044 \pm .044$ \\
\hline & & $\mathrm{F}$ & 3 & $17.59 \pm .60$ & $7.95 \pm .04$ & $8.15 \pm .34$ & $7.3 \pm .7$ & $1.018 \pm .029$ \\
\hline \multirow[t]{2}{*}{ FLA } & Florida & $\mathbf{M}$ & 5 & $18.38 \pm .53$ & $8.90 \pm .17$ & $9.36 \pm .16$ & $6.2 \pm 1.4$ & $.935 \pm .050$ \\
\hline & & $\mathrm{F}$ & 4 & $18.06 \pm .50$ & $8.44 \pm .12$ & $9.04 \pm .12$ & $8.5 \pm 1.0$ & $.985 \pm .045$ \\
\hline SMX & Mexico, southern & $\mathbf{F}$ & 1 & 19.38 & 8.44 & 8.68 & 10.0 & .964 \\
\hline \multicolumn{9}{|c|}{ Pinyon woodlands: } \\
\hline NEV & Nevada, central & $\mathrm{F}$ & 1 & 19.6 & 7.96 & 7.25 & 4.0 & .841 \\
\hline \multirow{2}{*}{ WOC } & California, Woodfords & $\mathbf{M}$ & $\begin{array}{l}1 \\
2\end{array}$ & $19.43 \pm .00$ & $\begin{array}{l}8.44 \\
8.68\end{array}$ & $\begin{array}{c}9.26 \\
8.59 \pm .39\end{array}$ & $\begin{array}{c}9.0 \\
10.5 \pm .5\end{array}$ & $\begin{array}{c}.981 \\
1.093^{ \pm} .010\end{array}$ \\
\hline & & $\mathrm{F}$ & 1 & 20.40 & 7.86 & 8.32 & 10.0 & 1.067 \\
\hline \multicolumn{9}{|c|}{ Mixed woodlands-mostly oak: } \\
\hline \multirow[t]{2}{*}{ BCS } & Baja California Sur, tip & $\mathbf{M}$ & 5 & $19.79 \pm .42$ & $8.76 \pm .21$ & $8.29 \pm .24$ & $9.8 \pm 1.3$ & $1.034 \pm .036$ \\
\hline & & $\mathrm{F}$ & 2 & $19.23 \pm .31$ & $8.22 \pm .18$ & $8.39 \pm .11$ & $8.5 \pm .5$ & $1.059 \pm .026$ \\
\hline \multirow[t]{2}{*}{ EPT } & Texas, Edwards Plateau & $\mathbf{M}$ & 5 & $20.18 \pm .24$ & $8.80 \pm .03$ & $8.75 \pm .13$ & $8.2 \pm 1.0$ & $1.014 \pm .034$ \\
\hline & & $\mathrm{F}$ & 5 & $19.09 \pm .52$ & $8.43 \pm .18$ & $8.25 \pm .18$ & $8.0 \pm .7$ & $.978 \pm .024$ \\
\hline \multirow[t]{2}{*}{ NEM } & Mexico, northeastern & $\mathbf{M}$ & 3 & $20.33 \pm .46$ & $8.63 \pm .00$ & $8.77 \pm .31$ & $8.7 \pm 1.5$ & $1.001 \pm .034$ \\
\hline & & $\mathrm{F}$ & 3 & $18.89 \pm .71$ & $8.48 \pm .12$ & $8.29 \pm .16$ & $8.3 \pm 1.3$ & $.973 \pm .072$ \\
\hline \multicolumn{9}{|c|}{ Mixed woodlands-mostly pinyon: } \\
\hline \multirow[t]{2}{*}{$\mathrm{COL}$} & Colorado & $\mathbf{M}$ & 6 & $20.11 \pm .23$ & $8.14 \pm .21$ & $8.01 \pm .08$ & $6.7 \pm .4$ & $.898 \pm .021$ \\
\hline & & $\mathrm{F}$ & 5 & $19.38 \pm .09$ & $8.03 \pm .09$ & $8.15 \pm .08$ & $5.4 \pm .7$ & $.826 \pm .053$ \\
\hline \multirow[t]{2}{*}{ AZA } & Arizona, northern & M & 4 & $19.11 \pm .41$ & $7.99 \pm .27$ & $7.95 \pm .35$ & $8.0 \pm 1.8$ & $.869 \pm .044$ \\
\hline & & $\mathrm{F}$ & 6 & $19.54 \pm .32$ & $8.15 \pm .11$ & $8.26 \pm .19$ & $5.8 \pm .8$ & $.881 \pm .027$ \\
\hline NMX & New Mexico, central & $\mathrm{F}$ & 2 & $17.80 \pm .44$ & $8.09 \pm .17$ & $7.89 \pm .05$ & $8.5 \pm 2.5$ & $.974 \pm .063$ \\
\hline \multirow[t]{2}{*}{ DMT } & Texas, Davis Mountains & $\mathbf{M}$ & 2 & $19.56 \pm .08$ & $8.41 \pm .15$ & $8.55 \pm .43$ & $8.0 \pm 1.0$ & $.915 \pm .060$ \\
\hline & & $\mathrm{F}$ & 3 & $18.43 \pm .23$ & $7.83 \pm .05$ & $8.43 \pm .28$ & $4.3 \pm 1.3$ & $.883 \pm .052$ \\
\hline \multirow[t]{2}{*}{ NWM } & Mexico, northwestern & $\mathbf{M}$ & 2 & $19.16 \pm .37$ & 8.54 & $8.67 \pm .17$ & $6.5 \pm .5$ & $.906 \pm .036$ \\
\hline & & $\mathrm{F}$ & 3 & $18.61 \pm .47$ & $8.35 \pm .07$ & $8.42 \pm .22$ & $7.7 \pm 1.9$ & $.871 \pm .059$ \\
\hline \multirow[t]{2}{*}{ WPC } & California, Whale Peak & $\mathbf{M}$ & 3 & $19.88 \pm .48$ & $8.28 \pm .21$ & $8.82 \pm .13$ & $6.7 \pm .9$ & $.964 \pm .044$ \\
\hline & & $\mathbf{F}$ & 8 & $18.68 \pm .31$ & $8.13 \pm .10$ & $8.45 \pm .14$ & $5.9 \pm 1.0$ & $.916 \pm .023$ \\
\hline
\end{tabular}




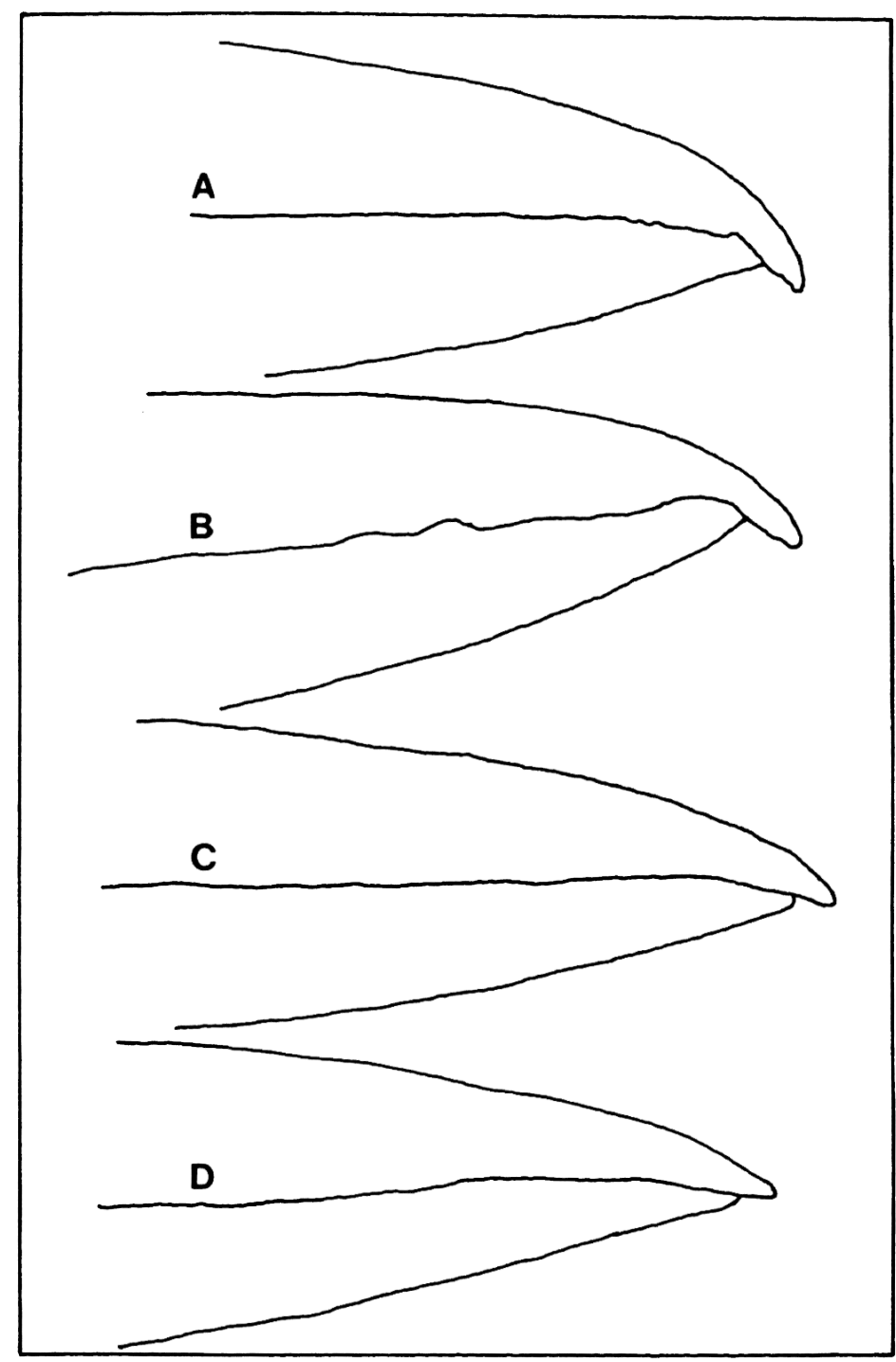

FIG. 2.-Four examples of scrub jay bill shapes showing the range of variation within the species.

I performed all statistical analyses using the Statistical Analysis System (SAS 1987). I remeasured on different days 22 individuals from two adjacent localities in southern California, including completely redrawing and digitizing bills, and calculated repeatabilities of character measurements as the squared Pearson product-moment correlation coefficient between the two sets of measurements. I excluded characters having repeatabilities less than 0.7 from subsequent analyses. Patterns of correlation between characters were inspected for redundancy. I tested all characters for departure from normality with the Shapiro-Wilk statistic (SAS 1987). 


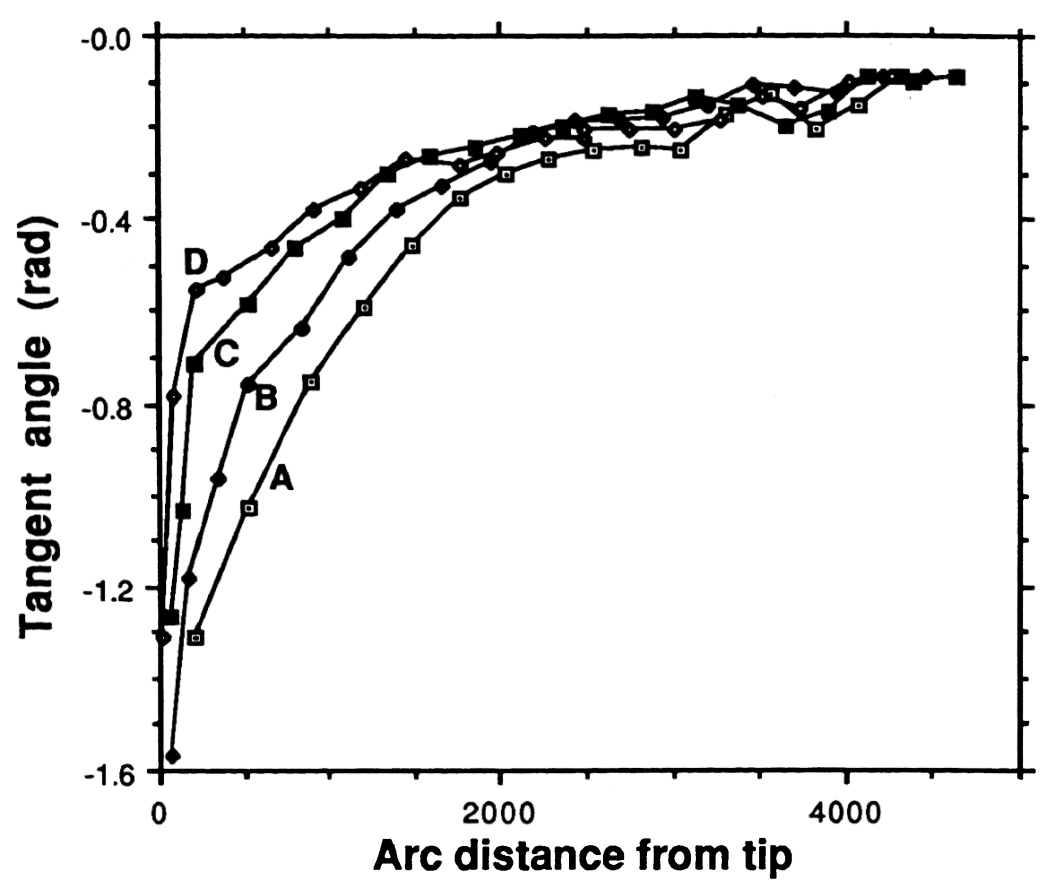

Fig. 3.-Tangent-angle functions for the four scrub jay bills $(A-D)$ shown in fig. 2

I assessed nongeographical variation using MANOVA, testing the effects of age, sex, and season individually, while controlling for the effects of the other variables and geographical variation. I tested the significance of between-locality variation using additional MANOVAs. I investigated phenetic similarity among populations using cluster analysis of Euclidean distances between standardized site means by the unweighted pair-group method of analysis (UPGMA).

\section{Phylogenetic Tests}

In an earlier study of evolutionary relationships of populations of the entire genus Aphelocoma, I examined allozyme frequency variation in 615 Aphelocoma jays collected at 66 sites across the United States and Mexico (Peterson 1990a, 1992). To provide outgroups for phylogenetic analysis, 70 individuals of 17 other corvid species were also analyzed. In all, variation at 29 loci was studied, and allele homologies among populations were checked carefully. Complete allozyme frequency tables and distance matrices are provided elsewhere (Peterson 1990a).

Phylogenetic hypotheses were derived from the allozyme data by a variety of methods that are summarized in an earlier article (Peterson 1992). Although UPGMA and single-linkage analyses were compromised by differences in evolutionary rates between lineages, Fitch-Margoliash and cladistic analyses converged on the same phylogenetic hypothesis. Fitch-Margoliash analyses of all scrub jay populations revealed the basal divergence of populations of Mexico and the Great Basin and Rocky Mountains of the United States and the subsequent derivation of populations of the oak woodlands of California, Oregon, and Baja 
California. Fifteen of the 23 nodes were stable to a jackknife manipulation (Lanyon 1985); none of the uncertainty indicated by unstable nodes affected the conclusions of the present study.

Cladistic analyses in which alleles were coded as characters revealed the same basic structure but were compromised by homoplasy resulting from nondetection of alleles in some population samples. Hence, in an effort to maximize detection of alleles in the operational taxonomic units (OTUs), I combined data on alleles detected in sets of populations corresponding to the subspecies groups of Pitelka (1951) and analyzed the relationships of regional groupings of Aphelocoma jays. The resulting single shortest tree was similar to that produced by the FitchMargoliash analyses, and, although jackknifing this data set revealed some instability in the nodes of relationships of scrub jays, the phylogenetic hypothesis used here was supported (Peterson 1992). Alternative hypotheses on the only major uncertainties in the phylogenetic hypothesis for scrub jays, the placement of the populations of Florida and Santa Cruz Island, had no effect whatsoever on the results reported here.

For the purposes of this study, it was necessary to generate a fully dichotomous tree of the relationships of individual populations for which morphometric data were available. Hence, the phylogenetic hypothesis for scrub jay populations used here is based on allele frequency variation in 292 individuals from 17 sites approximately matching the sites for the bill shape analyses (Peterson 1990a, 1992). These data were analyzed using a Fitch-Margoliash analysis (FITCH program of the PHYLIP package; Felsenstein 1989) of Rogers's genetic distances (as modified by Wright 1978) between populations (Peterson 1990a). Because the algorithm for reconstructing ancestral character states requires dichotomous trees, I did not use any "checks" of support for particular nodes. To obtain a character describing bill shape for phylogenetic analysis, I coded bill shape as pointed or curved based on results of the cluster analyses described above. Using the MacClade package (version 2.1; Maddison and Maddison 1987), I estimated the most parsimonious sequence of ancestral states and character-state change.

RESULTS

\section{Geographical and Nongeographical Variation}

Repeatabilities of five of the seven characters were greater than $70 \%$; the remaining two characters (PARAMA, PARAMB) had repeatabilities of less than $50 \%$ and so were excluded from further analysis. No intercharacter correlation exceeded 0.7; hence, no character was excluded on the basis of redundancy. One character distribution departed significantly from a normal distribution (HOOK: Shapiro-Wilk statistic, $W=0.966, P \leq .025 ; P>.22$ for all other characters). However, when only adult individuals were analyzed, the departure from normality in HOOK became nonsignificant, so no transformations of scale were employed.

In the MANOVA of variation due to nongeographical factors, controlling for variation among localities, significant effects of age $(P \leq .03)$, sex $(P \leq .0001)$, and season $(\boldsymbol{P} \leq .001)$ were evident. In general, younger individuals, females, 

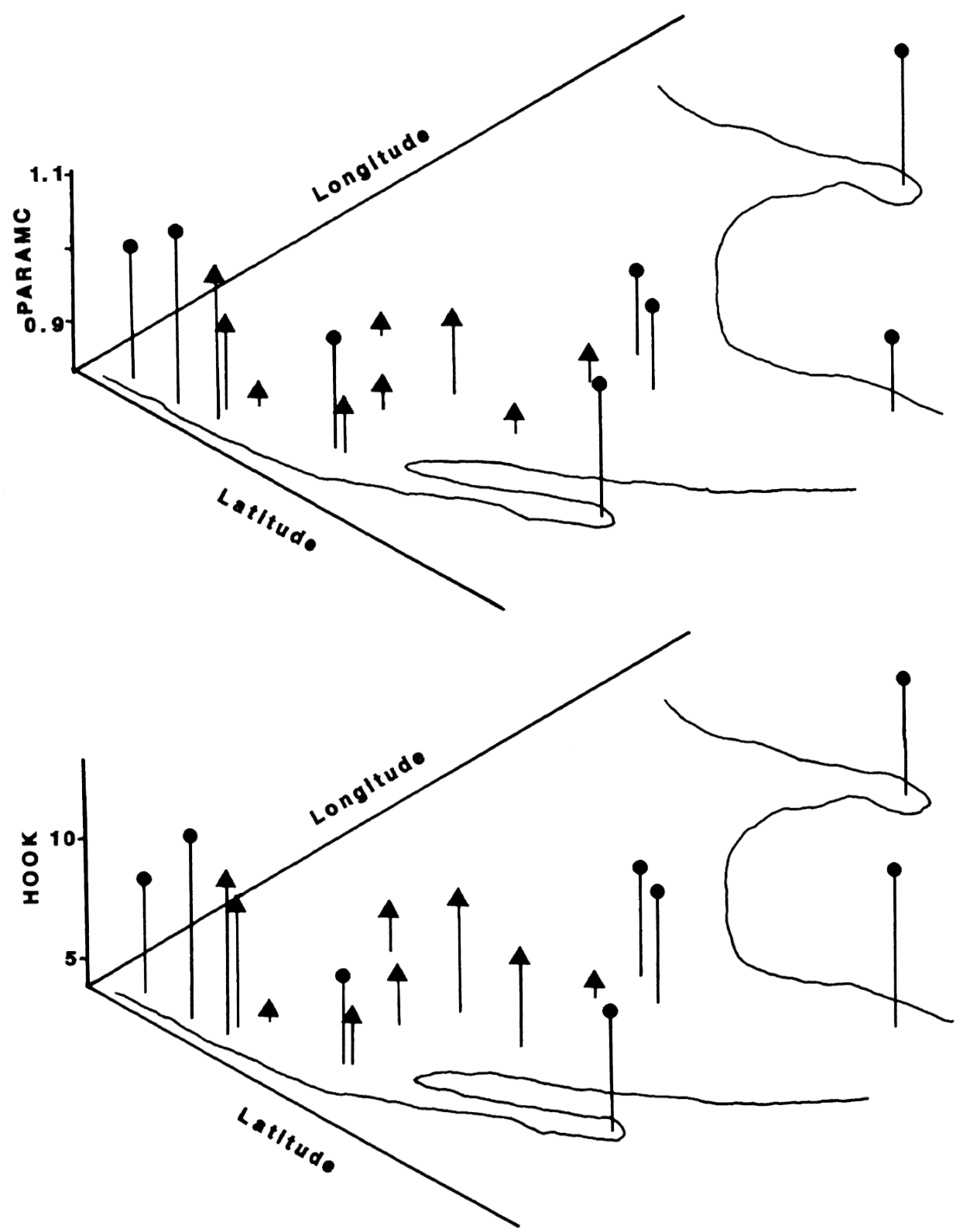

FIG. 4.-Geographical variation in the characters HOOK and PARAMC in after secondyear female scrub jays in North America. Spikes topped by a triangle indicate populations in pinyon-juniper woodland; those topped by a circle indicate populations in oak woodland. 


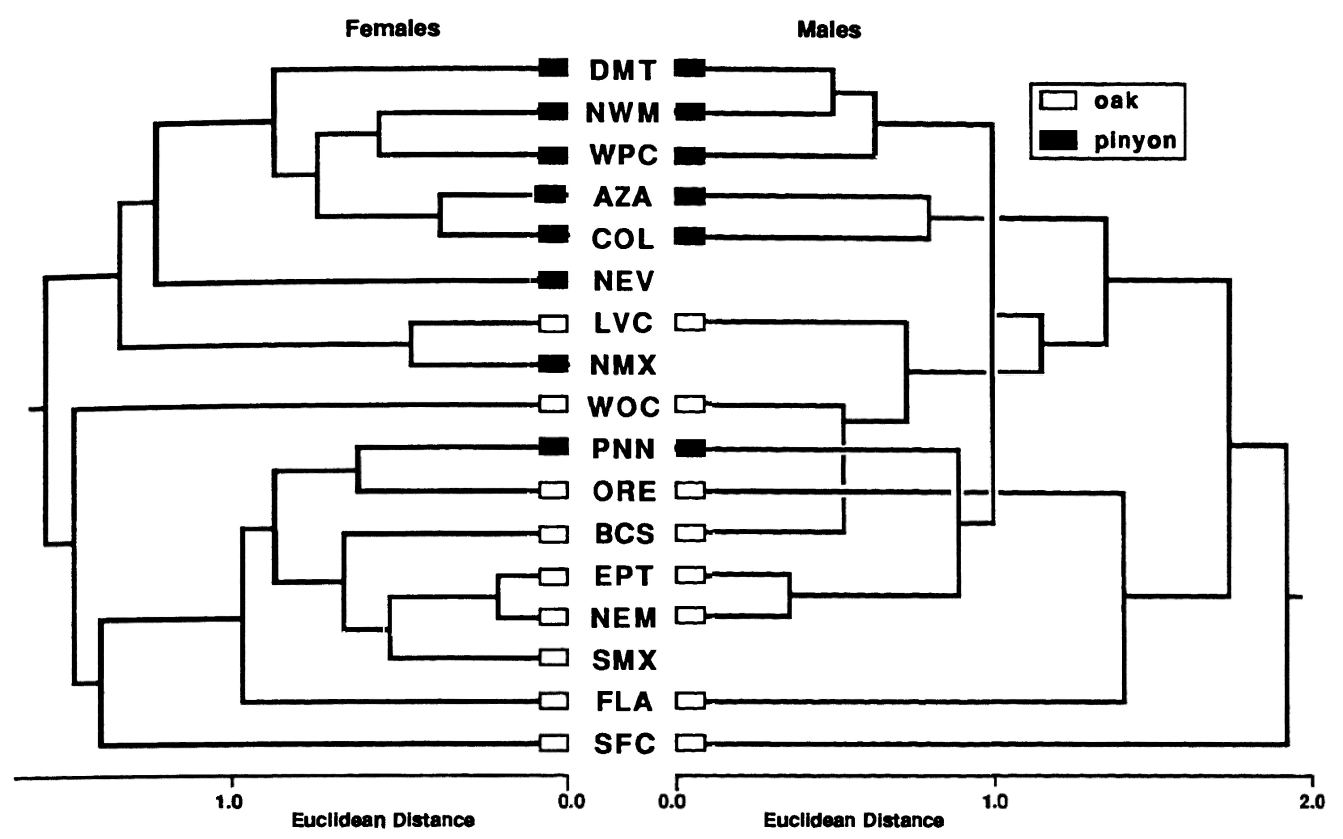

FIG. 5.-Phenogram summarizing the results of a UPGMA analysis of patterns of similarity among bill shapes of males and females of 17 scrub jay populations.

and birds from fall had more pointed bills. Eliminating individuals of all ages except after second-year (full adults) and analyzing sexes separately, the effect of season became nonsignificant $(\boldsymbol{P}>.29)$, so further analyses were based on a reduced group of 100 after second-year individuals from 17 localities, with sexes treated separately (table 1).

A MANOVA of this reduced set of individuals yielded highly significant amonglocality differences within each sex (fig. 4) $(P<.0001)$. One-way ANOVA comparisons of populations in oak versus pinyon habitats indicated significant differences in at least one of the sexes in four of the five characters (all except LENGTH; in seven of $10, P<.05$ ). Hence, bill form and habitat use are significantly associated in scrub jays.

In several characters, populations of the interior western United States and northwestern Mexico were similar and were distinct from populations to the east, west, and south (two examples in fig. 4; patterns in other characters were similar, though somewhat less clear-cut). Three pairs of populations in this study were located on either side of contact zones between the two habitats (i.e., in Texas, DMT vs. EPT; in the Lake Tahoe region of Nevada, WOC vs. PNN; and in southern California, LVC vs. WPC; fig. 1). In two of the three cases, the pinyonjuniper population of these pairs differed in the direction of having a longer, more pointed bill than the oak population.

Cluster analyses of bill forms of females indicated that the populations form two discrete clusters (fig. 5). Eight of the nine populations (88.9\%) of one cluster were populations of oak habitats; seven of the eight populations $(87.5 \%)$ in the 


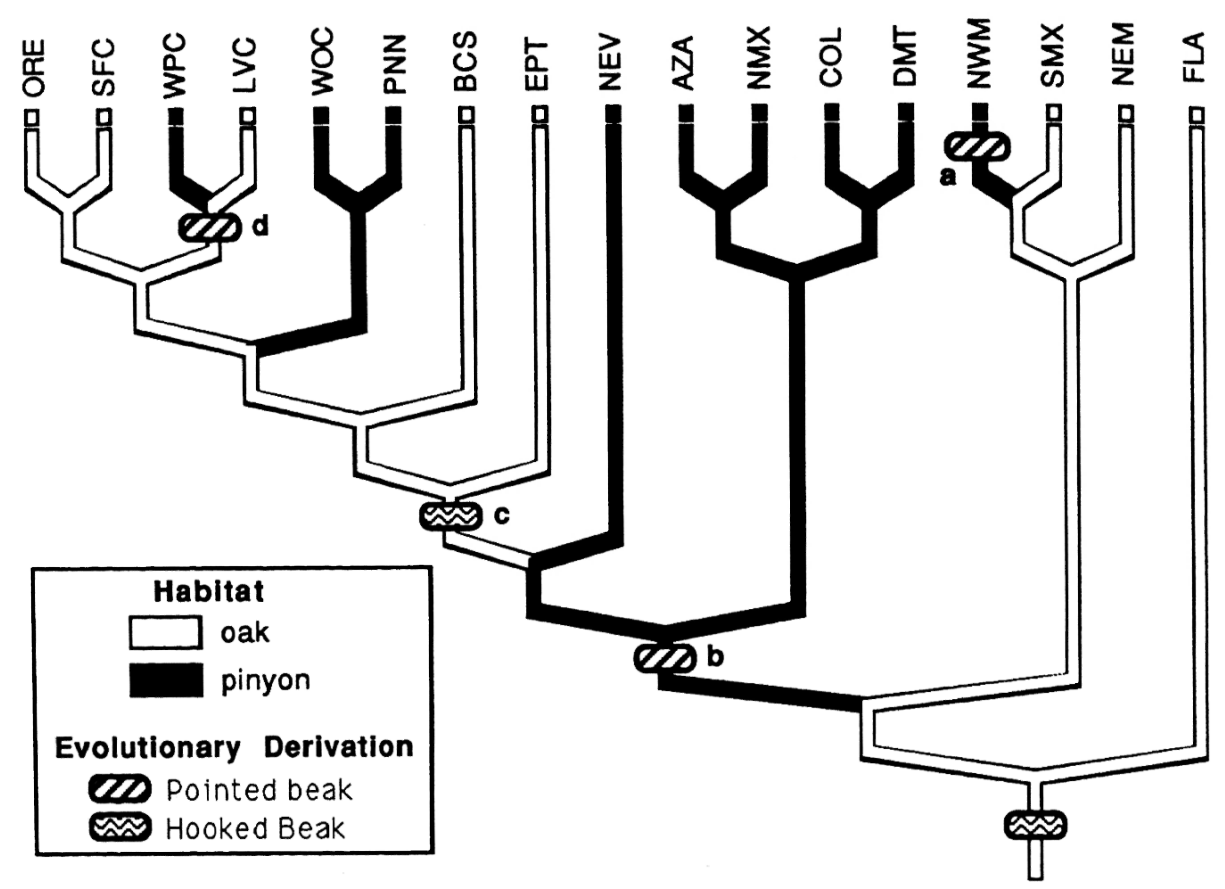

Fig. 6.-Phylogeny of populations of scrub jays showing the most parsimonious reconstruction of the pattern of change of bill shape and habitat use in the history of the species.

other cluster were populations of pinyon-juniper habitats. Hence, only three out of 17 populations clustered with populations of the "wrong" habitat type (significantly different from random assortment, binomial test, $P<.01$ ). Patterns in males were somewhat similar to those in females (fig. 5), with the major exceptions to the pinyon-oak dichotomy being in the transitional populations EPT, NEM, LVC, and WOC and the sometimes pinyon-living BCS populations. For males, statistical testing was not possible because the phenogram lacked a basal bifurcation dividing the taxa in two groups.

Therefore, pointed bills and pinyon-juniper habitats and hooked bills and oak habitats were significantly associated in geographical comparisons of female scrub jays, with bill shapes falling into two discrete clusters, each consisting largely of populations living in one of the two habitat types.

\section{Phylogenetic Tests}

Potential sister taxa for scrub jays (Aphelocoma ultramarina and Aphelocoma unicolor) have hooked bills (Peterson 1992; A. T. Peterson, unpublished manuscript). Both of these taxa live in oak woodland and feed on acorns in a manner similar to that of scrub jays. Hence, based on outgroup comparisons, it was reasonable to assume that hooked bills and living in oak habitats were the primitive states for scrub jays and that the pointed bill form and living in pinyon woodlands were derived subsequently.

Reconstruction of ancestral character states for habitat use indicated at least three invasions of pinyon habitats in the history of scrub jays (fig. 6). Early in the 
history of the species, scrub jays invaded the pinyon woodlands of northwestern Mexico and the southwestern United States; later, they reinvaded oak woodlands, this time in California. More recently (probably in the last 10,000 yr), from California, scrub jays reinvaded pinyon woodlands in the Lake Tahoe area and along the western edge of the Mojave Desert (Peterson 1990b). An equally parsimonious scenario of multiple invasions of California oak woodlands by pinyonliving populations was considered extremely unlikely on geographical grounds (Peterson 1990b).

For bill shape of female scrub jays, the two equally parsimonious scenarios each involved four evolutionary changes: either $(a)$ independent derivations of the pointed bill form in northwestern Mexico, much of the Great Basin and Rocky Mountains, Nevada, and the southern California desert-edge populations; or $(b)$ derivations of the pointed bill form in northwestern Mexico and the interior western United States, subsequent loss (reversal to the hooked form) before the derivation of the population of the Edwards Plateau, Texas, and the populations of California, and rederivation in the southern California desert-edge populations (fig. 6). Given that the Nevada and other Great Basin and Rocky Mountain populations are geographically continuous and highly interconnected genetically (Peterson $1990 a$, in press), the hypothesis of independent derivations in these groups (scenario $a$ ) seemed implausible. It therefore seemed that scenario $b$ is the bestsupported historical hypothesis. Because the northwestern Mexican population was not consistently placed as the sister group to populations in southern Mexico in more detailed analyses (Peterson 1990a, 1992), a hypothesis of independent derivation in that population may not be well supported. However, in all phylogenetic analyses, the southern California desert-edge populations without exception clustered within the oak-living populations of California, Oregon, and Baja California (Peterson 1990a). Hence, a hypothesis of at least two and as many as four independent derivations of the pointed bill shape from populations with hooked bills was strongly supported.

\section{DISCUSSION}

\section{Genetic Basis of the Differences}

The results of this study showed a close correlation between the occurrence of two distinct bill forms and habitat use in scrub jays. Phylogenetic analyses indicated that the pointed bill form was derived at least twice under similar ecological circumstances. However, the question of whether the difference in morphology is based on genetic differences needs clarification before the adaptive hypothesis can be considered further.

An alternative to the adaptive explanation is that the differences documented above represent a phenotypic (nongenetic) response to environmental influences of the two habitats (e.g., nutrition, abrasion from handling foods). Critical experimental crosses of populations with different bill forms have yet to be conducted. Hence, a genetic basis is not definitely established for the phenotypic differences.

Preliminary experiments suggest that scrub jay bill shapes are not very plastic in response to different diets. Four nestling scrub jays were taken from a nest 
near Davis, California, and raised to independence on turkey starter. For the experimental manipulation, the jays were divided into two pairs. One was fed a diet including a variety of hard-shelled nuts, which the birds spent large amounts of time opening, and the other was fed exactly the same diet, but with the nut shells removed. Hence, two of the four jays used their bills frequently to open hard-shelled food items, whereas the other two used their bills only to pound soft items into edible-sized pieces. After more than a year on these two diets, although differences in degree of wear on the cutting edges of the bills were evident, the curvature of the culmen and presence of a hook at the bill tip were unaffected by the experimental manipulation. Hence, it does not appear that wear associated with opening hard-shelled nuts has a strong effect on bill morphology in scrub jays.

Geographical evidence also suggests that a genetic basis to the differences does exist. Populations of hook-billed, oak-living California scrub jays have invaded pure pinyon-juniper woodlands in the Pine Nut and Virginia mountains near Lake Tahoe in western Nevada (PNN sample) (Peterson 1991). These populations show no evidence of development of a pointed bill (figs. 4 and 5), even though they live in pinyon-juniper woodland visually and floristically indistinguishable from the woodlands in which pointed-bill forms are found to the east and south (Critchfield and Little 1966; A. T. Peterson, personal observation). Hence, although conclusive experiments demonstrating heritability of the bill shape differences have yet to be conducted, geographical evidence suggests that the differences indeed have a genetic basis.

\section{Feeding Behavior}

Because bill shape and habitat use are strongly associated in scrub jays, both across space and across phylogeny, the hypothesis of an adaptive basis to bill shape variation is supported. In the following sections, I attempt to establish that the different food types characteristic of oak versus pinyon habitats serve as a causal factor in the apparent adaptive shift.

Zusi (1987) presented detailed descriptions of acorn-opening behavior of Florida scrub jays. Here, I supplement those observations with details relevant to the ideas developed in this article. The observations presented below are based on 2 $\mathrm{yr}$ of observation in my home of four tame, captive scrub jays from oak woodland near Davis, California, and on several weeks of observation of scrub jays in the long-term study population at Archbold Biological Station in Florida.

A jay presented with an acorn generally flies to a log or thick branch and holds the nut tightly against the branch with its longitudinal axis parallel to the branch. Florida scrub jays and adult California scrub jays hold the nut with the inner toes (digits 2 and 3) of both feet; juvenile California scrub jays at times use one foot only to hold the nut, which usually proves ineffective. The jay pounds the acorn using the lower mandible, with the tips of the bill held 2-3 mm apart, until a longitudinal crack forms in the acorn shell. At this point, the jay reaches in and pulls out the nut meat whole; pounds the exposed portion of the nut with both tips of the bill, breaking off and eating small pieces of the nut meat; or grasps the hull along the far side of the crack between the tips of the bill and rips it off 
TABLE 2

\begin{tabular}{|c|c|c|}
\hline \multirow[b]{2}{*}{ BILL FORM } & \multicolumn{2}{|c|}{ FunCtional IMPLICATION } \\
\hline & Acorns & Pine Nuts \\
\hline Short and hooked & $\begin{array}{l}+ \text { Hook as lever } \\
+ \text { Better braced }\end{array}$ & $\begin{array}{l}\text { - Hook prevents opening wide } \\
\text { - Cannot reach nuts }\end{array}$ \\
\hline Long and pointed & $\begin{array}{l}\text { - Poor leverage } \\
\text { - Not well braced }\end{array}$ & $\begin{array}{l}+ \text { Wide gape in confined space } \\
+ \text { Better reach }\end{array}$ \\
\hline
\end{tabular}

with a twist or push of the head, often in the same motion as pounding. Large chunks of nut meat are pounded with one or both tips of the bill into small pieces, which are either eaten or stored in the throat.

Scrub jays living in pinyon-juniper woodlands dedicate much time to harvesting and storing pinyon nuts, even to the point of risking aggressive encounters with larger species (e.g., Aphelocoma ultramarina) (A. T. Peterson, personal observation). Scrub jays are apparently incapable of opening closed pinyon cones as do Clark's nutcrackers (Nucifraga columbiana) and pinyon jays (Gymnorhinus cyanocephalus) (Vander Wall and Balda 1981). Because cones are closed during the early part of the seed harvest, scrub jays occasionally harass and steal pinyon nuts from Clark's nutcrackers but are otherwise unable to obtain pinyon nuts at that time. Later, when the cones open, scrub jays extract seeds from cones by probing with the bill while either hovering or perching below the cone (Vander Wall and Balda 1981).

\section{Functional Implications}

The information presented above on scrub jay bill shapes and the largely dichotomous ecological variation in the species (Peterson and Vargas 1993) suggests that the functional implications of variation in form and ecology can be viewed as a $2 \times 2$ contingency table of functional efficiencies (table 2). If each bill form functions most efficiently in the habitat in which its bearers live, then the hooked bill/acorn-eating and pointed bill/pinyon-nut-eating cells on the diagonal should have higher functional efficiencies than the off-diagonal cells. These discussions of functional efficiencies are not intended as adaptive hypotheses; they are simply a consideration of the relative efficiencies of different morphologies in different circumstances.

Two aspects of bill form have obvious functional implications: bill length and presence of a hook. Presence of a hook has clear advantages for opening acorns and disadvantages in extracting pinyon seeds. As described above, to open acorns, jays pound with the tip of the lower jaw, but once a crack is opened, they use the tips of both jaws to break off pieces of acorn shell. This task is accomplished with the tip of the mandible inside the nut and the tip of the maxilla clamped on the outer surface of the nut. The head is either pushed forward or twisted to one side to break off the shell. The hook at the end of the maxilla lends 

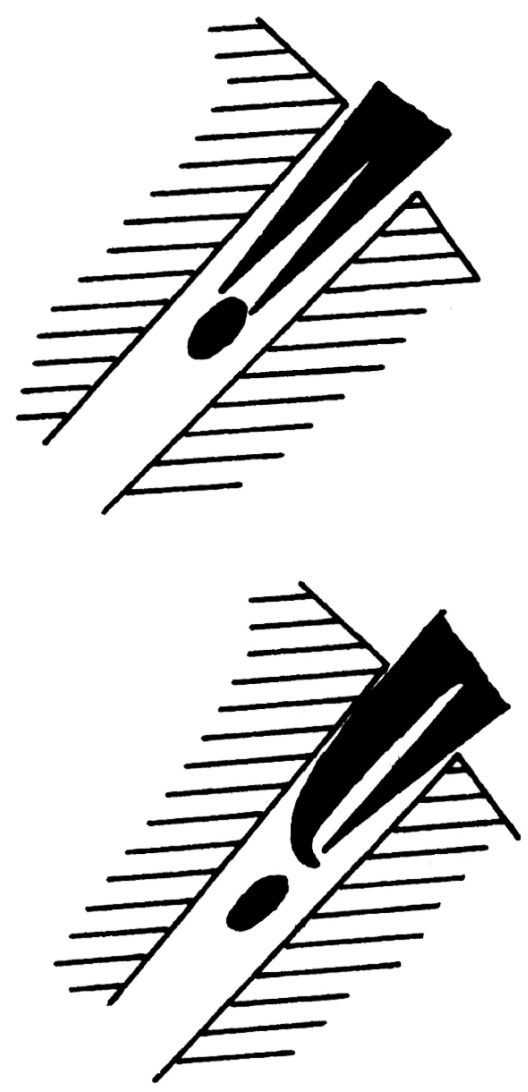

FlG. 7.-Diagrams of behaviors involved in harvesting pinyon nuts in which the presence of a hook at the tip of the bill yields a functional disadvantage.

extra leverage during this step and hence provides a functional advantage in opening acorns.

The bill hook, however, is decidedly disadvantageous in extracting pinyon nuts. Pinyon nuts are smaller than acorns and do not have particularly strong shells, so the problem is extracting the nuts from the cones rather than opening them. Pinyon cones are heavily armored, and scrub jays are apparently unable to open them (Vander Wall and Balda 1981). Instead, scrub jays must wait until the cones open as they dry, then reach in between the scales and pull out the nuts. As is evident from figure 7, a bill hook reduces considerably the ability to open the bill tips and grasp an object in a confined space.

Apparent functional trade-offs also exist regarding bill length for the two food types. For pounding a hard object such as an acorn, the best structure is heavy but short, so that the energy of the blows is concentrated at the point of contact. A short bill, however, would certainly be of reduced utility in extracting pinyon seeds, because of reduced ability to reach the axis of wider pinyon cones (especially Pinus monophylla). A limit probably also exists on how short a bill can be for feeding on acorns, because, below a certain length, the bill tips cannot open wide enough to grasp a large object (W. J. Bock, personal communication). 
Hence, as seen in table 2, short, hooked bills are probably more efficient functionally in feeding on acorns than on pinyon nuts, and long, pointed bills are probably more efficient functionally in feeding on pinyon nuts than on acorns. Feeding on these two types of nuts, each with a particular set of problems involved in its exploitation, may be a causal factor in producing the geographical variation documented above.

\section{Phylogeny and Historical Geographical Scenario}

It is important to bear in mind that the phylogenetic hypothesis employed in this study is indeed a hypothesis. It is based on analyses of protein variation in a large series of individuals from numerous localities across the species' range, and the results are consistent across both phenetic and cladistic analyses (Peterson 1992). Still, phylogenetic inference is not an easy task, especially for such closely related taxa. Further studies based on other character sets (e.g., DNA sequences) are planned. Nevertheless, I feel that this phylogenetic hypothesis is sufficiently well supported that exploration of its implications is warranted.

The phylogenetic analysis of changes in bill shape presented above, combined with historical biogeographical hypotheses developed in an earlier article (Peterson 1990a), suggests a historical geographical scenario of range expansion and adaptation in scrub jays (fig. 8). The ancestral scrub jay probably evolved from a gray-breasted jay (A. ultramarina) population in eastern or southeastern Mexico (Peterson 1990a, 1992) and had a hooked bill (fig. 8A). As it expanded its range northwest into the pinyon-juniper woodlands of the Great Basin, a pointed bill form was derived (fig. $8 B$ ). Later, upon invasion of the extensive coastal oak woodlands of California, a hooked form was rederived (fig. $8 C$ ). When these populations invaded relict woodlands of the pinyon $P$. monophylla on the western edge of the Mojave Desert in southern California from oak woodlands to the west (Critchfield and Little 1966), a pointed bill form once again was derived (fig. 8D).

It would seem likely that morphological adaptation would be associated with invasion of a new habitat. In the parsimony reconstruction, three of the four hypothesized evolutionary changes in bill shape occur on the same branch as invasion of a new habitat type (fig. $6 a, b$, and $c$ ); in the remaining case (fig. $6 d$ ), morphological change appears to precede invasion of the new habitat. Throughout, however, ambiguities in assigning habitat types to intermediate populations may have interfered with correct reconstruction of evolutionary history, and the sample size ( $N=$ four evolutionary changes) is too small to permit statistical testing. Hence, an understanding of the actual ordering of evolutionary changes must await detailed analyses of more specimens.

\section{Conclusions and Future Directions}

Brandon (1990) suggested that the ideally complete adaptive explanation would include the following elements: (1) evidence that selection has occurred, (2) an ecological explanation of why some types are better adapted, (3) evidence that the traits involved are heritable, (4) information on patterns of gene flow and distribution of selective environments, and (5) phylogenetic information concerning directionality of character change. Bill shape variation in scrub jays has a 


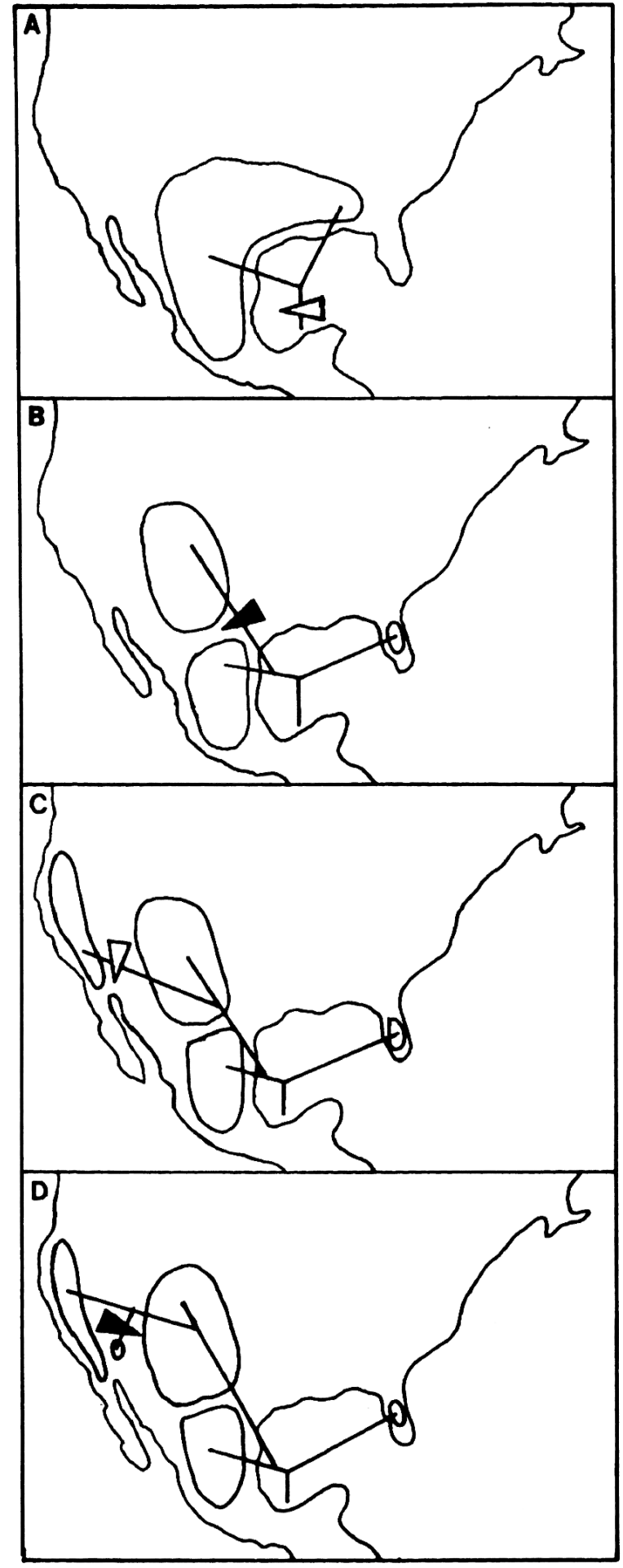

FIG. 8.-Historical geographical reconstruction of bill shape evolution in scrub jays. Solid triangles indicate the derivation of a pointed bill form; open triangles indicate the derivation of a hooked bill form. See text for detailed explanation. 
strong geographical component that is closely and significantly associated with habitat use and food distribution. The bill shapes of females from 17 populations form two clusters, one of bills that are relatively short and hooked at the tip (found in oak woodlands) and one of bills that are long and pointed (found in pinyon-juniper woodlands). Each bill form is apparently most efficient at exploiting the foods present in its habitat, and some evidence indicates a genetic basis to the bill shape differences. The high degree of genetic structuring of scrub jay populations documented elsewhere (Peterson 1990a, in press), and the existence of these populations in a broad mosaic of habitats (fig. 1) make adaptation to exploitation of each habitat credible. These forms appear to have been derived and lost at several points in the phylogenetic history of the species, correlating with invasions of pinyon and oak habitats. The hypothesis that much of the variation in scrub jay bill shape is adaptive is hence strongly supported by several lines of evidence filling requirements 2-5, assuming requirement 1 to be true.

It is perhaps surprising that scrub jays have adapted so strikingly to exploiting one food item in their habitats. Especially when feeding young, jays commonly capture reptiles, amphibians, and large insects, and invertebrates make up a substantial portion of the diet year-round (Woolfenden and Fitzpatrick 1984). Still, the jays apparently place great importance on nut meats, given the amount of time and energy that they invest in harvesting, storing, and defending these resources (DeGange et al. 1989). Nutritional studies aimed at clarifying why nut meats are critical would be most informative.

Badly needed are laboratory experiments on the jays and their bill shapes: experimental crosses are needed to establish firmly the genetic basis of the difference between the bill morphs and perhaps to ascertain how many genes are involved in the difference. Experimental tests of the functional efficiencies of the two bill forms would be important in confirming the predicted trade-offs in functional efficiency. Moreover, interesting patterns of geographical variation in bill shapes exist within pinyon-inhabiting scrub jay populations (western populations have longer and thinner bills than eastern populations), perhaps related to differences in cone morphology of the various pinyon species (e.g., $P$. monophylla, Pinus edulis, and Pinus cembroides) (A. T. Peterson, unpublished manuscript). Similar geographical patterns may be manifested by other birds that feed on pinyon nuts in these habitats, such as pinyon jays (A. T. Peterson, unpublished manuscript). Study of morphometric variation in regions presenting a mosaic of oak and pinyon habitats, such as in southern California or southeastern Arizona, would provide an interesting test of which resource is evolutionarily more important to the jays in areas where both are available. The interaction between variation in nut production by pinyons and oaks and jay morphology and behavior has implications for other aspects of the biology of the jays, such as year-round defense of territories and dispersal distances, and yet it remains completely unstudied.

\section{ACKNOWLEDGMENTS}

A hearty thanks is due D. Clayton for his help in many phases of this study, from collecting critical specimens to discussions of geographical differences and 
their importance. B. Chernoff provided valuable counsel on morphometric methods, W. Bock and M. LaBarbera pointed out important functional implications, J. Koeppl and V. Pacheco helped with designing features of the data collection and analysis, and B. Plybon helped immensely in deriving geometrical equations. S. Altmann provided challenging discussions of testing genetic determination of differences. J. Fitzpatrick and G. Woolfenden kindly allowed access to the study population of Florida scrub jays. J. Bates, S. Hackett, J. V. Remsen, and T. Schulenberg gave helpful critical comments on the manuscript. F. Pitelka gave interest and valuable insight throughout. I was supported by grants from the National Science Foundation Dissertation Improvement Program (BSR-8700850), the National Geographic Society, the Field Museum of Natural History, and the Hinds Fund of the University of Chicago during this study.

LITERATURE CITED

Benkman, C. W. 1988. On the advantages of crossed mandibles: an experimental approach. Ibis 130:288-293.

Bock, W. J. 1966. An approach to the functional analysis of bill shape. Auk 83:10-51.

Bookstein, F. L. 1978. The measurement of biological shape and shape change. Lecture Notes in Biomathematics 24:1-63.

Brandon, R. N. 1990. Adaptation and environment. Princeton University Press, Princeton, N.J.

Brooks, D. R., and D. A. McLennan. 1991. Phylogeny, ecology, and behavior. University of Chicago Press, Chicago.

Critchfield, W. B., and E. L. Little, Jr. 1966. Geographic distribution of the pines of the world. U.S. Department of Agriculture Miscellaneous Publications 991:1-97.

DeGange, A. R., J. W. Fitzpatrick, J. N. Layne, and G. E. Woolfenden. 1989. Acorn harvesting by Florida scrub jays. Ecology 70:348-356.

Endler, J. A. 1986. Natural selection in the wild. Princeton University Press, Princeton, N.J.

Felsenstein, J. 1985. Phylogenies and the comparative method. American Naturalist 125:1-15. 1989. PHYLIP, phylogeny inference package: version 3.2 manual. University of Washington, Seattle.

Goodwin, D. 1976. Crows of the world. Cornell University Press, Ithaca, N.Y.

Gould, S. J., and R. F. Johnston. 1972. Geographic variation. Annual Review of Ecology and Systematics 3:457-498.

Gould, S. J., and R. C. Lewontin. 1979. The spandrels of San Marco and the Panglossian paradigm: a critique of the adaptationist program. Proceedings of the Royal Society of London B, Biological Sciences 205:581-598.

Harvey, P. H., and M. D. Pagel. 1991. The comparative method in evolutionary biology. Oxford University Press, Oxford.

Hood, W. G. 1987. Polynomial curve fitter. Byte 6:155-160.

Hope, S. 1989. Phylogeny of the avian family Corvidae. Ph.D. diss. City University of New York.

James, F. C. 1970. Geographic size variation in birds and its relationship to climate. Ecology 51:365-390.

Lanyon, S. M. 1985. Detecting internal inconsistencies in distance data. Systematic Zoology 34:397-403.

Maddison, W. P., and D. R. Maddison. 1987. MacClade, version 2.1. (A computer program distributed by the authors: W.P.M., Department of Ecology and Evolutionary Biology, University of Arizona, Tucson; D.R.M., Department of Entomology, University of Arizona, Tucson.)

Mayr, E. 1963. Animal species and evolution. Columbia University Press, New York. 1988. Toward a new philosophy of biology. Harvard University Press, Cambridge, Mass.

Peterson, A. T. 1990a. Evolutionary relationships of the Aphelocoma jays. Ph.D. diss. University of Chicago. 
1990b. The birds of Eagle Mountain, Joshua Tree National Monument, California. Western Birds 21:127-135.

1991. Gene flow in scrub jays (Aphelocoma coerulescens): frequency and direction of movement. Condor 93:926-934.

1992. Phylogeny and rates of molecular evolution in the Aphelocoma jays (Corvidae). Auk 109:133-147.

In press. Genetic variation and differentiation in the Aphelocoma jays (Aves: Corvidae). Auk.

Peterson, A. T., and N. Vargas B. 1993. Ecological diversity in scrub jays (Aphelocoma coerulescens). Pages 309-317 in T. P. Ramamoorthy, A. Lot, R. Bye, and J. Fa, eds. The biological diversity of Mexico: origins and distribution. Oxford University Press, Oxford.

Pitelka, F. A. 1945. Pterylography, molt, and age determination of American jays of the genus Aphelocoma. Condor 47:229-260.

1951. Speciation and ecologic distribution in American jays of the genus Aphelocoma. University of California Publications in Zoology 50:195-464.

SAS. 1987. SAS/STAT guide for personal computers. Version 6 ed. SAS Institute, Cary, N.C.

Turcek, F. J., and L. Kelso. 1968. Ecological aspects of food transportation and storage in the Corvidae. Communications in Behavioral Biology Part A, Original Articles 1:277-297.

Vander Wall, S. B. 1990. Food hoarding in animals. University of Chicago Press, Chicago.

Vander Wall, S. B., and R. P. Balda. 1981. Ecology and evolution of food-storage behavior in coniferseed-caching corvids. Zeitschrift fur Tierpsychologie 56:217-242.

Woolfenden, G. E., and J. W. Fitzpatrick. 1984. The Florida scrub jay: demography of a cooperativebreeding bird. Princeton University Press, Princeton, N.J.

Wright, S. 1978. Evolution and genetics of populations. Vol. 4. Variability within and among natural populations. University of Chicago Press, Chicago.

Zink, R. M., and J. V. Remsen, Jr. 1986. Evolutionary processes and patterns of geographic variation in birds. Current Ornithology 4:1-69.

Zusi, R. L. 1987. A feeding adaptation of the jaw articulation in New World jays (Corvidae). Auk 104:665-680. 